\title{
LAZAR, M. M. (ORG.) FEMINIST CRITICAL DIS- COURSE ANALYSIS. GENDER, POWER AND IDE- OLOGY IN DISCOURSE. NEW YORK: PALGRAVE MACMILLAN, 2005, 251 PÁGS.
}

\section{Resenhado por: Luzia Rodrigues da Silva}

A obra Feminist critical discourse analysis, organizada por Michelle M. Lazar, apresenta vários estudos que abordam a relação entre discurso e gênero social - especificamente o feminino - tendo a Análise de Discurso Crítica (ADC) como referência teórico-metodológica.

Além de Michelle M. Lazar, o livro conta com a contribuição das autoras Janet Holmes, Luísa Martin-Rojo, Concepción Gómez Esteban, Ruth Wodak, Kathryn A. Remlinger, Mary Talbot, Izabel Magalhães, Erzébet Barát e do autor Carlos A. M. Gouveia.

No capítulo introdutório, intitulado "Politicizing gender in discourse", Michelle M. Lazar, além de apresentar uma visão panorâmica de todo o volume, chama-nos a atenção para a relevância de trabalhos como este, que apresenta como objetivo a ampliação do conhecimento sobre poder e ideologia atravessados no discurso. A autora sugere que poder e ideologia sustentam uma ordem social, ordem essa ligada à discussão sobre os gêneros sociais.

Esse volume, portanto, representa uma significativa contribuição para os estudos e as mudanças no que se refere às questões relativas ao gênero social, poder e ideologia, na modernidade tardia. Essas questões vêm assumindo formas cada vez mais complexas e, por isso mesmo, devem ser postas em pauta como pontos relevantes para reflexão. Nesse sentido, representa o livro uma oportunidade de desenvolvimento de uma Consciência Lingüística Crítica ${ }^{1}$ sobre as relações assimétricas entre os gêneros sociais e sobre o papel da linguagem como discurso na construção dessas relações, tanto em termos de sua reprodução como de sua transformação. A linguagem aqui é veiculada ao poder, podendo ser usada para manter o status quo ou para combatê-lo.

1. A expressão Consciência Lingüística Crítica surgiu como uma proposta de lingüistas da Universidade de Lancaster, na Grã-Bretanha, de considerar a linguagem como constitutiva em relação à sociedade, nos planos institucional, ideológico e das relações de poder (Fairclough, 1992: 7). 
Um ponto de relevante significação é a reflexão de Lazar, ainda no capítulo introdutório, a respeito dos estudos da Análise de Discurso Crítica sobre gênero social, com um foco voltado para as relações de gênero de visão feminista crítica. A autora justifica tal entrelaçamento, sobretudo, pondo diante dos nossos olhos a pedra angular da ADC e de muitos estudos da linguagem feminista: a perspectiva crítica diante das relações de desigualdades representadas nos contextos sociais e atravessadas no discurso, e a motivação de transformação das condições vigentes. Desse modo, podemos afirmar, a ADC feminista toma a linguagem como prática social (Chouliariaki e Fairclough, 1999), como discurso, enfim, que, conforme a visão da dialética de Fairclough (trad. 2001), contribui para a reprodução e a manutenção da ordem social e também para a resistência e a transformação dessa ordem. Assim, é possível afirmar que a Análise de Discurso Crítica feminista está posicionada numa perspectiva política sobre gênero e, como tal, vê-se preocupada com a desmistificação de gênero, poder e ideologia no discurso e com a transformação social.

Este estudo configura-se, portanto, como assevera Lazar, em uma 'pesquisa orientada para a práxis crítica' posto que mobiliza a teoria com o intuito de construir consciência crítica e desenvolver estratégias feministas que visam à resistência e à mudança.

A contribuição desse livro se deve, também, à discussão da concepção de gênero como estrutura ideológica, pois como enfatiza Lazar "a concepção de gênero dominante é entendida como uma estrutura ideológica que divide as pessoas em duas classes, homens e mulheres, com base em uma relação hierárquica de dominação e subordinação, respectivamente" (p. 7). Essa ordem é aqui posta em discussão.

A noção de reflexividade também é contemplada pela autora que emprega o conceito de Giddens (1991). A reflexividade, então, diz respeito a uma constante revisão, por parte dos atores sociais, de aspectos da atividade social, de modo a delinear sua própria prática subseqüente. É esse um fenômeno da vida social contemporânea, que é, nesse livro, apresentado como uma importante faceta da prática da ADC feminista. A interdisciplinaridade, intertextualidade e interdiscursividade também são temas, de relevante importância para análise discursiva, que permeiam a discussão da autora e, para isso, ela faz ecoar as vozes de Fairclough (trad. 2001)) e Bakhtin (1981).

Quanto à organização do volume, está dividido em duas partes que estão assim intituladas: "Post-equality? Analyses of subtle sexism" e "Emancipation and social citizenship: analyses of identity and difference". A primeira parte é composta de seis capítulos e a segunda, de quatro. Lazar acentua que as seções trazem preo- 
cupações feministas contemporâneas, que a ADC feminista propõe investigar. Além disso, é também projeto desse volume apresentar pesquisas de diferentes contextos geográficos. Por isso, cada capítulo discute uma realidade específica. Isso amplia o olhar do leitor ou da leitora, estendendo a sua percepção e criticidade.

Os capítulos da primeira seção, "Post-equality? Analyses of subtle sexism”, trazem para a discussão os vários contextos que, aparentemente, reconhecem a visibilidade e a ascendência de mulheres nos domínios públicos de trabalho remunerado, na política e na educação, bem como os papéis visíveis de homens no domínio privado. Porém, os estudos revelam que, atrás da aparência de emancipação, a discriminação sexista se desenvolve de forma sutil, velada, nesses contextos, sobretudo por meio dos mecanismos de naturalização. As autoras, diante desse quadro, proclamam a necessidade de mudanças na estrutura de gênero e na mentalidade das pessoas. Em vários capítulos, são apresentadas as maneiras com que mulheres (e homens), dentro de estruturas organizacionais, negociam e desafiam as ideologias e estruturas de poder dominantes, indicando possibilidades de mudanças.

O Capítulo 2, "Power and discourse at work: is gender relevant?", assinado por Janet Holmes, que dá início à seção, revela que, embora as mulheres estejam ocupando posições de poder no local de trabalho, elas são ainda coagidas a atenuar "seus estilos de discursos pelo suposto comportamento interacional 'feminino' apropriado" (p. 20). Isso equivale a dizer que não é permitido à mulher deslocar-se de estereótipos femininos já naturalizados; que a ela não cabe posicionar-se discursivamente, no exercício de sua atividade, conforme padrões que são apenas aceitáveis para os homens. Sobre isso, Deborah Cameron (1992: 41) acentua que "ainda é comum as práticas femininas serem definidas à luz das práticas masculinas (...). Isso logo faz com que o comportamento lingüístico 'desviante' da mulher seja explicado em termos estereotipados e sexistas".

Com esse estudo, desenvolvido na Nova Zelândia, Holmes explicita que os estereótipos de gênero estão, ainda hoje, interiorizados, de maneira velada, nas interações do local de trabalho, contribuindo para formas sutis de discriminação.

Luisa Martín-Rojo e Concepción Gómez Esteban, no Capítulo 3, "The gender of power: the female style in labour organizations", com base em uma pesquisa desenvolvida em organizações de trabalho na Espanha, refletem sobre as relações das mulheres com os princípios de liderança e autoridade no seu espaço de trabalho, quando em posição de poder. A maneira com que tais mulheres estabelecem vínculos de trabalho com os homens, seus colegas, que as excluem; a forma com que conquistam o respeito por parte de seus subor- 
dinados que delas desconfiam, são também pontos de reflexão nesse capítulo. Destacam as autoras que "na busca de melhores condições, as mulheres são levadas a se adaptarem às formas e aos estilos dominantes, o que, por sua vez, pode resultar em uma 'desmulherização', ou seja, seu poder pode até ser aceito, mas elas não são vistas como femininas" (p. 75). Em posições de liderança, portanto, em sua relação com as instituições que ainda são caracterizadas por uma cultura masculina de dominação, a mulher enfrenta formas de discriminação e preconceito, o que acarreta implicações reais para seu desenvolvimento e promoção nas organizações de trabalho.

No Capítulo 5, "Negotiating the classroom floor: negotiating ideologies of gender and sexuality", Kathryn A. Remlinger examina a constituição de ideologias de gênero em sala de aula de uma universidade americana. Ela demonstra que ideologia de gênero e sexualidade são interdependentes. Negociadas conjuntamente, portanto, e constituídas através das atividades diárias dos estudantes, essas categorias configuram-se como construções fluidas. Essa idéia afina-se com o pensamento de Stuart Hall (1997: 7) a respeito da constituição das identidades. Para ele, as identidades representam uma "celebração móvel".

O estudo de Remlinger é de relevante significação, pois essa autora nos traz a discussão de como gênero e sexualidade afetam a aprendizagem e o processo de educação, de como "a estrutura e a prática da universidade afetam noções de gênero e sexualidade de estudantes e que diferença gênero e sexualidade produzem nas práticas cotidianas dos estudantes" (p.134).

Os capítulos da segunda seção, "Emancipation and social citizenship: analyses of identity and difference", desenvolvem uma discussão em torno da variedade de razões que revelam os entraves para a emancipação da mulher e a conquista de sua plena cidadania. Tais razões estão relacionadas, como demonstram os estudos das autoras e do autor dos referidos capítulos, com a relativa falta de programas de alfabetização para mulheres, a violência sistemática contra a mulher, a ausência dos direitos civis legalmente garantidos e a falta de uma esfera pública para a articulação de posições alternativas e de vozes femininas radicais. Ressaltamos que essas questões estão imbricadas a uma política de identidade e diferença e é por esse viés que elas estão aqui representadas.

Mary Talbot, no Capítulo 7, "Choosing to refuse to be a victim: 'power feminism' and the intertextuality of victimhood and choice", discute a violência contra as mulheres, em sociedades patriarcais. Tal violência, para Talbot, ocorre como forma de poder e controle sobre as mulheres.

A autora apresenta a National Rifle Association (NRA), uma organização poderosa dos Estados Unidos, que, aproveitando o medo da violência 
nas mulheres, que é legítmo, e as chamadas feministas que conclamam as mulheres a repudiar o status de vítimas, e movida por interesses comerciais lucrativos, constrói, discursivamente, em de suas campanhas publicitárias, uma identidade feminina somente fortalecida com o porte de armas. Essa situação relatada faz-nos pensar no fenômeno da desapropriação do discurso, um tema que não pode ser desconsiderado no jogo das discriminações. Daí, a relevância desse capítulo.

No Capítulo 8, "Interdiscursivity, gender identity and the politics of literacy in Brasil", Izabel Magalhães analisa a identidade de mulheres brasileiras em um estudo desenvolvido em dois programas de alfabetização de adultos. Servindo-se da Análise de Discurso Crítica, essa autora investiga voz e interdiscursividade em três diferentes gêneros discursivos, um jornal local, uma aula (discussão de textos) e entrevistas. Nessa investigação, ela foca "os caminhos em que as identidades das mulheres são textualmente mediadas em um contexto de mudança social" (p. 181).

Demonstrando, portanto, como as identidades femininas são recontextualizadas nos três diferentes gêneros, o estudo de Magalhães indica a co-existência de 'velhas' e 'novas' identidades - termos que retomam o seu trabalho "A critical discourse analysis of gender relations in Brazil" (1995) - entre as participantes dos referidos programas. Nesse sentido, a autora discute aspectos que contribuem para o fortalecimento e o enfraquecimento das mulheres. Além disso, apresenta a sua defesa a respeito da necessidade de investimento em educação de mulheres para que elas ocupem posições valorizadas na vida política e social. Demonstra a autora uma grande preocupação com as políticas de letramento.

Carlos A. M. Gouveia, com o Capítulo 10, "Assumptions about gender, power and opportunity: gays and lesbians as discursive subjects in a Portuguese newspaper", fecha o volume analisando a representação de gays e lésbicas como sujeitos discursivos em um dos mais importantes jornais publicados em Portugal, intitulado Diário de Notícias. Desse modo, ele lança luz sobre o preconceito naturalizado de que são vítimas os homossexuais.

Os estudos, que compõem esse volume, trazendo as particularidades de diferentes formas de opressão, de que, ainda, são vítimas as mulheres, em diferentes espaços geográficos, revelam que as mudanças locais e globais estão inscritas no contexto da modernidade tardia e que essas têm implicações na construção e constituição de identidadas femininas.

Feminist critical discourse analysis. Gender, power and ideology reafirma a posição da Análise de Dicurso Crítica no centro das discussões sobre linguagem e gênero social. Esse livro representa um olhar feminista crítico 
sobre as várias formas de discriminação numa ordem social que privilegia os homens como grupos sociais em detrimento às mulheres, e sobre as práticas, sobretudo as lingüísticas, que mantêm e reproduzem padrões de dominação. Além disso, este volume, interconectando feminismo e ADC, revela o seu significativo valor na produção de uma crítica voltada para a praxis, para a ação, contribuindo, dessa maneira, para encaminhar lutas de contestação e de mudanças.

\section{REFERÊNCIAS BIBLIOGRÁFICAS}

Bakhtin, M. The dialogical imagination (ed. M. Holquist). Austin: University of Texas Press, 1981.

Cameron, D. et al. Researching language: issues of power and method. London: Routledge, 1992.

Chouliaraki, L. \& Fairclough, N. Discourse in late modrnity: Rethinking Critical Discourse Analysis. Edimburgo: Edinburgh University Press, 1999.

Giddens, A. Modernity and self-identity: self and society in the late modern age. Cambridge: polity Press, 1991.

Fairclough, N. Discurso e mudança social. Trad. I. Magalhães et al. Brasília: Editora Universidade de Brasília, 2001.

(org.). Critical language awareness. Londres: Longman, 1992.

Hall, S. A identidade cultural na pós-modernidade. Trad. T. T. da Silva e G. L. Louro. Rio de Janeiro: DP \& A Editora, 1997.

Magalhães, I. A critical discourse analysis of gender relations in Brazil. Journal of Pragmatics, 23: 183-197, 1995.

Luzia Rodrigues da Silva-luzro7@yahoo.com.br 